\title{
Not - To - Do Recommendations and Informed Consent In The Health Department of A Comarcal Hospital
}

\author{
Miguel Angel García García* and María del Carmen Ortín Sorando \\ UCI Hospital de Sagunt Care and Information Patient Service (SAIP) of the Health Department of Sagunt, Spain \\ *Corresponding author: Miguel Angel García García, Intensive Care Unit, hospital de Sagunt, Valencia, Spain
}

\section{ARTICLE INFO}

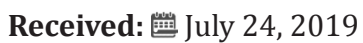

Published: 蔧 July 31, 2019

Citation: Miguel Angel García G, María del Carmen Ortín S. Not - To Do Recommendations and Informed Consent In The Health Department of A Comarcal Hospital. Biomed J Sci \& Tech Res 20(2)-2019. BJSTR. MS.ID.003416.

Keywords: Not - to - Do Recommendations; Informed Consent; Quality of health care; Physician -Patient relationship; Survey
ABSTRACT

Introduction: The commitment to quality in our work must be absolute. Important aspects in our daily practice should be the knowledge of the Not - To - Do Recommendations of our scientific society, and the correct realization of the Informed Consents.

Objectives: To know the degree of knowledge of the Not - To - Do Recommendations and the adequate realization of the Informed Consent in the professionals of the health department of a second level hospital.

Methods: An unrestricted survey filled by health professionals in the health area and focused on those 2 aspects.

Results: The recent formation in Informed Consent is scarce (23\% of professionals) The use of Informed Consent when indicated is 69.7\% (better in surgical specialties). The knowledge of the Not - To - Do Recommendations is scarce (32.6\%), although in the majority of the cases the professionals act appropriately without knowing them.

Conclusion: This work shows that the degree of knowledge of the Recommendations of Not to Do is scarce, and that the realization of the Informed Consent has several improvement areas to perform.

\section{Introduction}

As indicated by the Internal Regulation of the Functional Unit of Patient Quality and Safety (FUPQS) of the hospital de Sagunto [1], and all our recent legislation on quality addressed to health [2-4], the quality of care is a tool to improve health care within an area of respect for patients. This quality of care involves the commitment of the entire organization, with the provision of an effective and safe health care that meets the needs and expectations of patients and professionals, uses the knowledge based on the best available scientific evidence, makes an efficient use of resources, in a comfortable and safe care environment, and with an optimal personal treatment. The main objective of one of the strategic lines of work developed by this Functional Unit is to promote a bioethical culture, within the usual practice of the healthcare activity in the health department. For this reason, an assessment about the knowledge and use of "NOT - TO - DO" Recommendations (NTDR) and the use of the Informed Consent (IC) was made, managed by the different health professionals.

The NTDR are understood as generic behaviour patterns, within each specialty, that have traditionally been performed, but at the present time it no longer makes sense that they are carried out, because they are inappropriate, dangerous or not cost-effective [5]. The initiative "Commitment to the Quality of Scientific Societies in Spain" promotes the statement of these NTDR by scientific societies to reduce unnecessary sanitary interventions based on scientific evidence [6]. The IC is a document resulting from the communication between the health professional and the patient, where the first one informs in a sufficient and understandable way about the surgical, diagnostic or therapeutic procedure so that the patient participates in a voluntary way in the decision making regarding his health, being able to give its consent or not to said procedure [7]. All this is included in the Spaniard law 41/2002, of November 14, basic regulatory of the autonomy of the patient and of rights and obligations in matters of information and clinical documentation [4].

The members of the FUPQS of the Sagunt hospital considered to know the current situation of the health department in these two issues. So, a survey was conducted among health professionals to assess the degree of knowledge of the NTDR and the application of 
the IC in the daily activities of the staff of our hospital. In a second time, those actions that will be considered appropriate will be carried out to improve the use of the NTDR and the IC.

\section{Materials \& Methods}

A survey was conducted from September to December 2018 among professionals in the hospital de Sagunto health department, aimed at assessing their level of knowledge of RNTD and the realization of IC. The survey was given to several health professionals: doctors -residents and staff members-, nurses and physiotherapists who have NTDR -available in the web :

http: / / www.mscbs.gob.es / ca / organizacion/sns / planCalidadSNS/cal_sscc.htm.

It was anonymous. Its realization was discussed with the chiefs of hospital services, and its realization was commented in morning clinical sessions. Periodic visits were made to these services to favor / to remember the completion of the survey. Its implementation was also explained in a meeting of Primary Care coordinators, to extend the collection of data to the Primary Care services. The last filled questionnaires were collected, to proceed to the mathematical elaboration, at the end of December 2018.

\section{A. Section 1:}

The survey had 2 sections. The first section, referring to the NTDR, followed a simple pattern:

a) First question: do you know the NTDR promoted by your scientific society?

b) Second to sixth questions: affirmative statement of the question, exposed in such a way that its logical answer should be "NO".

\section{B. Section 2:}

The second section, referred to the IC, included 12 simple questions, directed to several aspects:

a) The health worker has recently received training on the proper performance of IC;

b) The physical and psychological preparation of the patient are appropriate, and the medication taken before carrying out the technique / procedure is right;

c) The explanation of the technique is adequate and detailed, evaluating patient benefits and risks and alternatives, and answering questions, both during the explanation and at the end of the interview;

d) The use of IC before performing usual techniques / procedures that have their established use is exhaustive; i. e., techniques such as programmed surgery, contrast-enhanced $\mathrm{CT}$, programmed coronary angiography, etc;

e) The possibility of using Oral Consent, if it is not possible to perform IC; and the option of tacit consent by the patient ("the patient relies of all the actions of his physicians / nurse / midwife / rehabilitator, in many occasions for reasons of comfort, speed, simplicity, etc, and the IC is not written.

The authors of the work asked the respondents of the survey that they respond according to their usual practice and not "what they know they should do", remembering the anonymity and NO intention to judge the usual practice of any professional. , and thanking the sincerity for the usefulness it entails that the results capture the reality in the daily work. If the answers to the survey are honest, the results of the study will describe the reality of their daily work. The survey was raised in order to be answered in a simple way affirmatively (YES) or negative (NO); the answers that did not fit exactly those items, or the blank answers, were attributed to those 2 items depending on the meaning of the question. As an example, the survey that was sent to medical specialists in Intensive Care is shown in Figures A \& B of the Appendix. Some hospital specialties (Otorhinolaryngology, Ophthalmology, Gynecology, Dermatology and hospital Gynecology and Primary Care Midwives) don't have NTDR; therefore, they didn't made a survey with NTDR questions and completed a survey focused on the realization of IC. Other services (Laboratory and Preventive Medicine) do not perform activities that require IC; analogously, his survey only reflected data regarding the RNTD. The survey tried to cover most of the medical services in the health department.

Categorical variables were defined: Service / specialty (35, see below), type of Service (Medical, Surgical, Central and Primary Care), and questions about NTDR and IC, which were answered with YES / NO. The answers on CI were expressed in percentages of affirmative answers. The statistical evaluation of differences in proportions / percentages yielded results that were mostly statistically significant, but it was decided to reflect only the percentages in the different sections, as a sample of the heterogeneity in all the services and aspects assessed. No other filiation data were collected (age, sex, time worked, staff or resident physician, etc).

The responses on NTDR were numerically assessed as the percentage of appropriate responses to these questions (Figure $\mathrm{C}$ of the Appendix). A scatterplot was made, with the previous knowledge of the existence of the NTDR represented in the abscissa, and the degree of coincidence with those NTDR in ordinates. The statistical management was done with the SPSS v15.0 package. The graphics were made with SPSS v.15.0 and EXCEL 97-2003.

\section{Results}

369 surveys were collected, corresponding to 363 physicians, nurses, physiotherapists and midwives; laboratory physicians gave us surveys of knowledge of recommendations of their 2 scientific societies. These health professionals represent around 59\% of the total health workers in the health department (617). We have collected 356 surveys referring to IC and 322 surveys referring to NTDR. The amount of services and service groups included is shown in Figure 1 and Figure D of the Appendix. The percentages 
of affirmative answers to the questions about IC, grouped according to the type of Service, are shown in Table 1. It can be seen that the recent formation in IC reaches $23 \%$ of professionals in the global of all services, with $14,6 \%$ in medical specialties, $25 \%$ in surgical specialties, and $28.8 \%$ in Primary Care. A low percentage of professionals accept a tacit consent $27.5 \%$ globally, with $21.3 \%$ in medical specialties, $34.4 \%$ in surgical specialties, and $27.6 \%$ in Primary Care). Other aspects, such as detailed explanation of the technique to be performed, physical-psychic preparation, and the oral consent in the place of an unrealizable IC, are variables among specialties, with values higher than $60 \%$ in most cases.

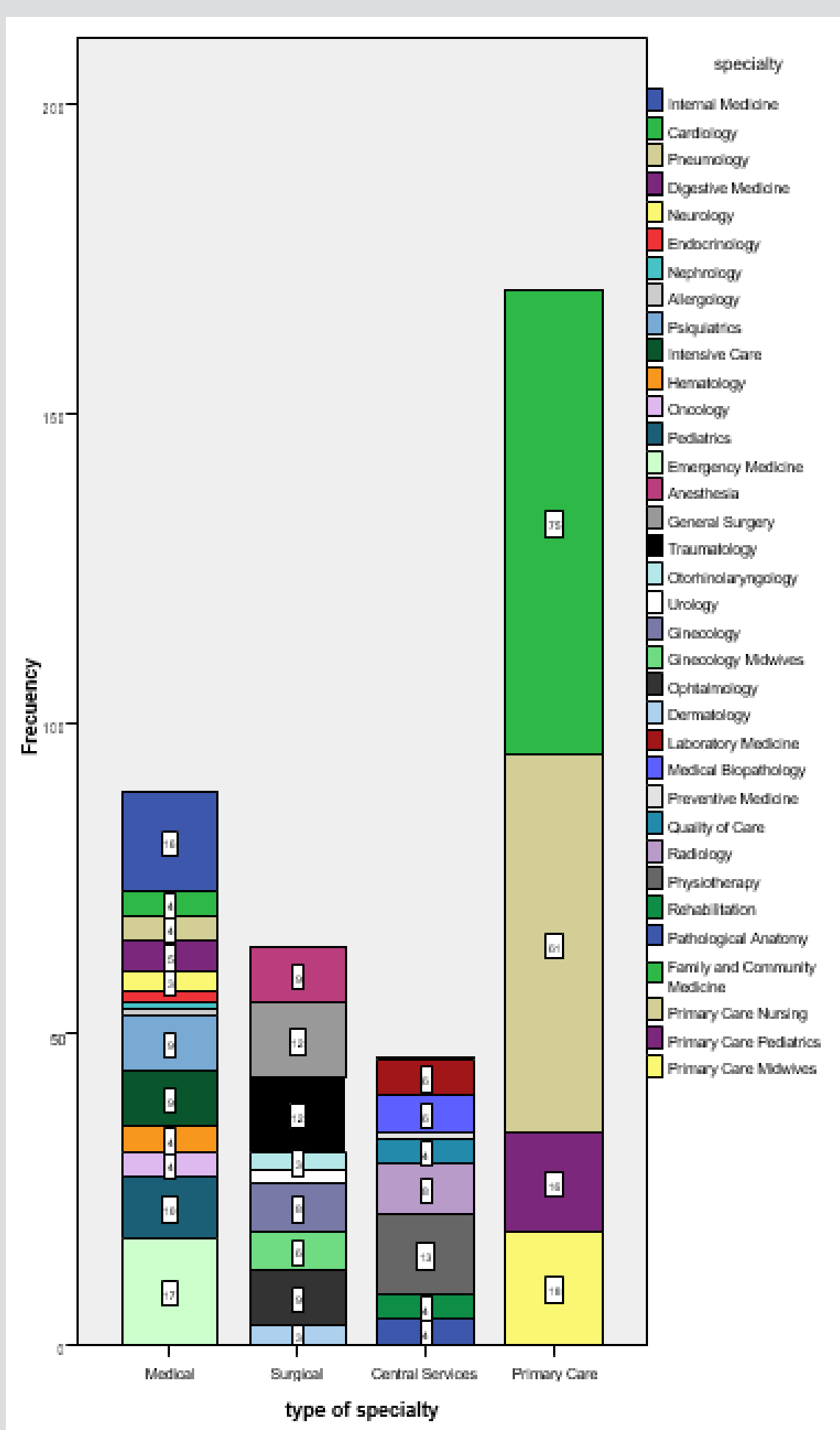

Figure 1: Stacked bar graph showing the number of members of each service, with the legend in colors on the right that shows the identity of each service. The services of 1 or 2 answers are not specified in the graph: Nephrology, Allergology and Preventive Medicine (1 response) and Endocrinology and Urology (2 responses). 
Table 1: Percentage of affirmative answers to each question about CI. Color code: Blue 100 - $80 \%$ affirmative answers; green 79.9 $60 \%$; yellow 59.9 - $40 \%$; orange 39.9 - $20 \%$; $<20 \%$ red. identifier of the question and text of the question indicated in the surve

\section{Consent?}

\section{Recent learning in IC?: Have you recently received learning on the completion of Informed}

Physical and psychic preparation?: Have you discussed with the patient the need for a physical and / or psychic preparation for the completion of the treatment / diagnostic test?

- Evaluation of diet and previous medication?: Have you evaluated with the patient the diet to follow, the previous medication and the necessary drugs for the completion of the treatment / diagnostic test?

Always use of IC if indicated?: Do you always use the Informed Consent by techniques or treatments in which its use is established?

Is tacit consent enough?: Do you think that the tacit consent of the patient is enough for all the actions that you do as a doctor?

Presentation as patient's responsible professional?: Do you present yourself as patient's responsable profesional?

Detailed explanation of the technique?: Do you explain to the patient, in detail, the technique to which he is going to submit?

Explanation of benefits and risks?: Do you explain to the patient, in an appropriate way, the benefits that are expected to be obtained, the risks, and the benefit / risk ratio of this technique?

- Explanation of alternatives?: Do you explain to the patient alternatives to the offered technique?

- $\quad$ Answer to questions raised by the patient?: Do you answer to all the doubts raised by the patient?

- $\quad$ Final question about if there is any doubt?: Do you finally ask the patient if he has any doubt in particular?

Raise oral consent if IC cannot be performed?: If informed consent cannot be obtained, do you consider the option of making oral consent?

\begin{tabular}{|c|c|c|c|c|c|c|c|c|c|c|c|c|c|}
\hline Specialty & $\mathbf{N}$ & 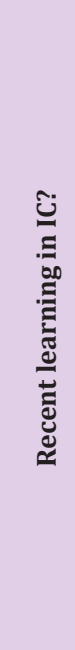 & 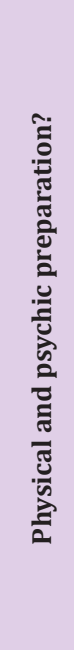 & 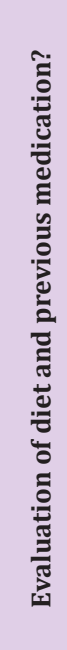 & 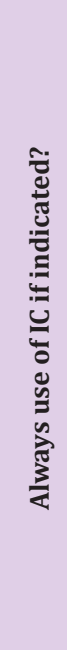 & 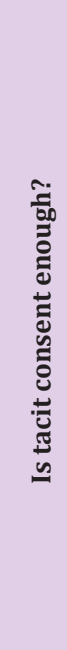 & 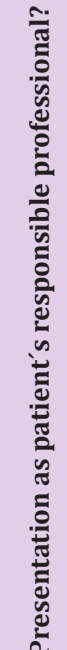 & 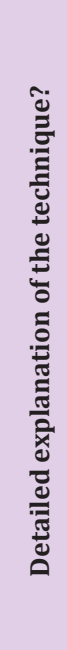 & 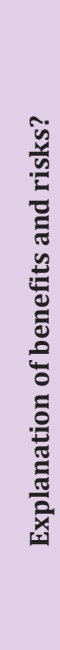 & 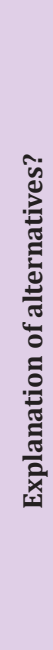 & 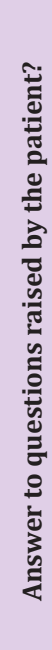 & 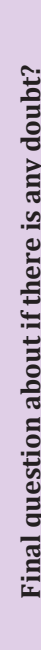 & 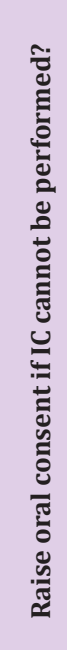 \\
\hline
\end{tabular}




\begin{tabular}{|c|c|c|c|c|c|c|c|c|c|c|c|c|c|}
\hline Medical & 89 & 14,6 & 75,3 & 78,7 & 77,5 & 21,3 & 96,6 & 84.3 & 80,9 & 71,9 & 95,5 & 92,1 & 77,5 \\
\hline Surgical & 64 & 25 & 64,1 & 79,7 & 90,6 & 34,4 & 84,4 & 79,7 & 90,6 & 87,5 & 96,9 & 82,8 & 57,8 \\
\hline Central Services & 33 & 12,1 & 48,5 & 39,4 & 48,5 & 30,3 & 48,5 & 75,8 & 69,7 & 69,7 & 75,8 & 60,6 & 45,5 \\
\hline Primary Care & 170 & 28,8 & 57,1 & 82,4 & 61,8 & 27,6 & 76,5 & 73,5 & 72,9 & 60,6 & 83,5 & 80,6 & 54,1 \\
\hline Global & $356(369)$ & 23 & 62,1 & 77 & 69,7 & 27,5 & 80,3 & 77,5 & 77,8 & 69,1 & 88,2 & 82 & 59,8 \\
\hline
\end{tabular}

A relevant aspect to assess is the completeness in the use of IC, if it is realized whenever its use is established, in surgical interventions, diagnostic techniques and therapeutic procedures. The meaning of the question is to assess if, at least, we provide the IC document to the patient in the procedures in which it is accepted. The other aspects, such as explaining to the patient what is the procedure to be performed, the assessment of the risk / benefit ratio, the description of possible complications and the resolution of any doubts the patient exposes, is assessed in the other sections, as already indicated. The spectrum of specialties reflected in Figure 2 is as follows: Surgical specialties are those that IC use is more frequently (90.6\%), followed by medical ones (77.5\%), those included in Primary Care ( 61.8\%), and finally those of Central
Services (48.5\%), for an overall affirmative response of $69.7 \%$. The lack of recent formation in IC of the different types of services is graphically evaluated in Figure $\mathrm{E}$ of the Appendix. The recent formation in IC has higher percentages in specialties of Primary Care $(28.8 \%)$ and surgical (25\%), and minor in medical specialties (14.6\%) and central services (12.1\%). The detailed assessment, service to service, of the aspect of recent formation in IC is shown in Figure $\mathrm{F}$ of the Appendix. Services with a huge healthcare burden, such as Internal Medicine in the hospital environment, or Family Medicine in the Primary Care, have a low percentage of recent formation in this aspect (25\% and $21.3 \%$, respectively). Other significant services within the hospital such as Surgery or Urgencies have lower percentages ( $0 \%$ and $5.9 \%$ ).

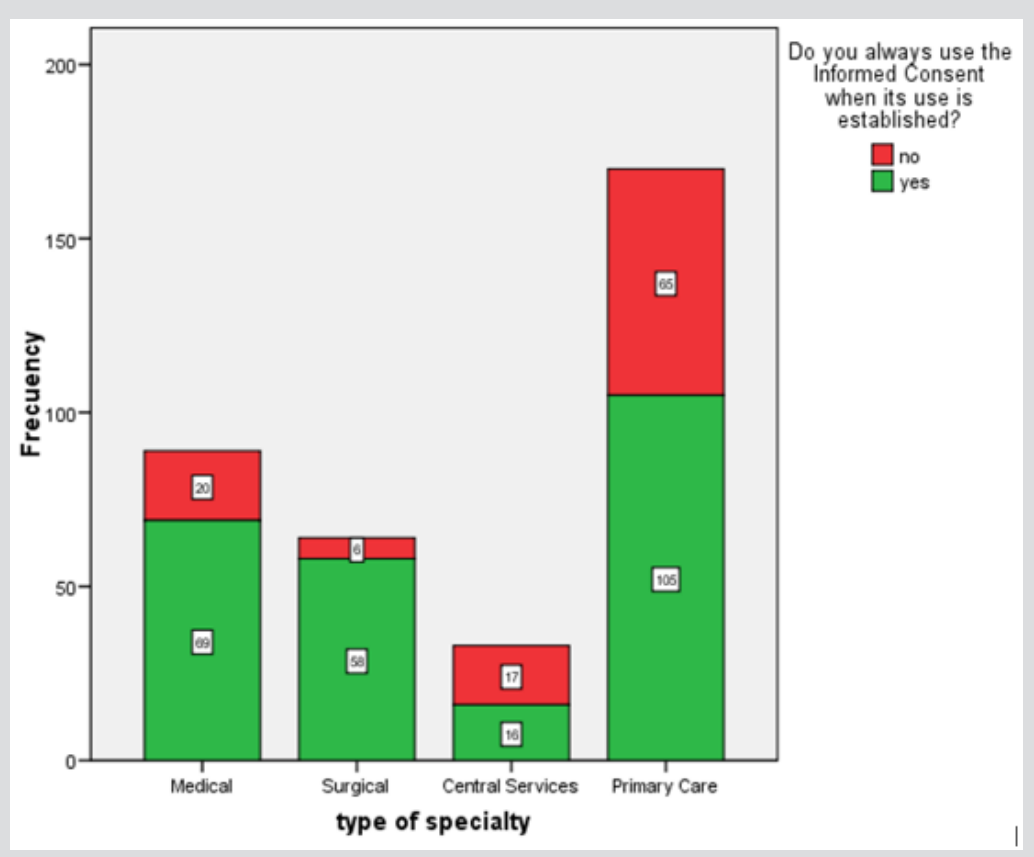

Figure 2: Stacked bar graph about the exhaustiveness in the use of IC for techniques / procedures in which its use is established.

The detailed description of the answers of the different specialties is shown in Table 2 . The lack of an adequate formation in IC are extendable to almost all specialties. The information about NTDR is discussed below. Figure 3 shows a very heterogeneous knowledge of these recommendations among the members of the consulted services, with 4 services with a knowledge percentage higher than $80 \%$, and an overall figure of $32.6 \%$. There is a possibility that health professionals do their work according to these recommendations without knowing them. The relationship between the degree of knowledge of the NTDR with the "good practice", that is, the coincidence with the NTDR, regardless of whether or not the recommendations are known (as we explained above, the percentage of appropriate responses), was graphically represented (Figure 4), and that relationship was valued mathematically with a linear regression. There is no linear relationship between both variables; there is a great dispersion of the cloud of points $(\mathrm{R} 2=$ $0.017=1.7 \%$ ), and the points are distributed in the upper part of the graph and not around the bisector; that is to say, the action of the health workers is adequate, or according to those NTDR, regardless of whether they know them or not. 
Table 2: Percentages of affirmative answers to the questions referred to the IC in the different specialties. Color code and meaning of the items in each column is the same as that indicated in table 1.

\begin{tabular}{|c|c|c|c|c|c|c|c|c|c|c|c|c|c|c|}
\hline 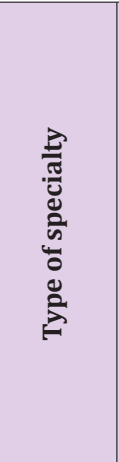 & $\begin{array}{l}\frac{3}{\pi} \\
\text { के } \\
\text { के }\end{array}$ & $z$ & 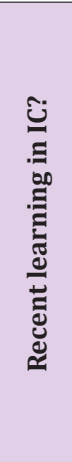 & 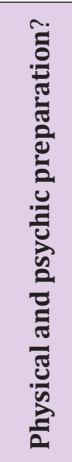 & 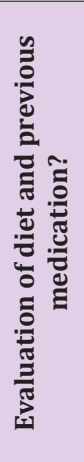 & 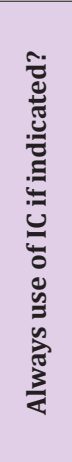 & 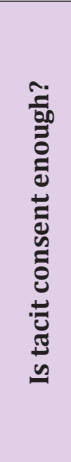 & 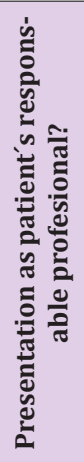 & 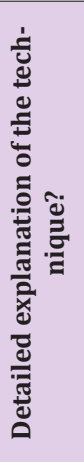 & 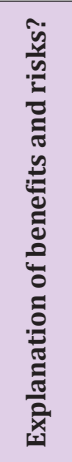 & 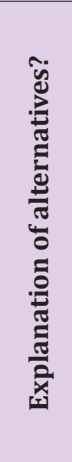 & 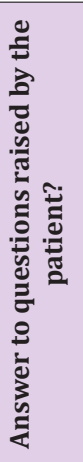 & 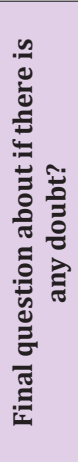 & 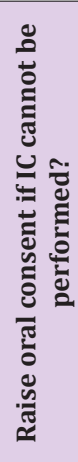 \\
\hline \multirow{14}{*}{ Medical } & Internal Medicine & 16 & 25 & 68,8 & 68,8 & 87,5 & 37,5 & 93,8 & 75 & 75 & 43,8 & 81,3 & 87,5 & 75 \\
\hline & Cardiology & 4 & 25 & 50 & 100 & 75 & 0 & 100 & 100 & 100 & 75 & 100 & 100 & 100 \\
\hline & Pneumology & 4 & 25 & 100 & 100 & 100 & 25 & 100 & 100 & 100 & 100 & 100 & 100 & 50 \\
\hline & Digestive Medicine & 5 & 0 & 60 & 100 & 100 & 20 & 100 & 100 & 100 & 80 & 100 & 80 & 40 \\
\hline & Neurology & 3 & 0 & 66,7 & 100 & 100 & 0 & 100 & 100 & 100 & 100 & 100 & 33,3 & 0 \\
\hline & Endocrinology & 2 & 0 & 100 & 100 & 100 & 100 & 100 & 100 & 100 & 100 & 100 & 100 & 50 \\
\hline & Nephrology & 1 & 0 & 100 & 100 & 100 & 0 & 100 & 100 & 100 & 100 & 100 & 100 & 100 \\
\hline & Allergology & 1 & 0 & 0 & 100 & 100 & 0 & 100 & 100 & 100 & 0 & 100 & 100 & 0 \\
\hline & Psichiatry & 9 & 11,1 & 88,9 & 66,7 & 55,6 & 22,2 & 100 & 77,8 & 88,9 & 100 & 100 & 100 & 77,8 \\
\hline & Intensive Care & 9 & 33,3 & 77,8 & 66,7 & 77,8 & 11,1 & 100 & 88,9 & 77,8 & 77,8 & 100 & 100 & 88,9 \\
\hline & Hematology & 4 & 0 & 100 & 100 & 0 & 0 & 100 & 100 & 100 & 100 & 100 & 100 & 100 \\
\hline & Oncology & 4 & 0 & 75 & 100 & 100 & 0 & 100 & 50 & 100 & 75 & 100 & 100 & 100 \\
\hline & Pediatrics & 10 & 20 & 90 & 100 & 60 & 20 & 100 & 100 & 80 & 90 & 90 & 100 & 100 \\
\hline & Emergency Medicine & 17 & 5,9 & 64,7 & 52,9 & 82,4 & 23,5 & 88,2 & 70,6 & 52,9 & 47,1 & 100 & 88,2 & 82,4 \\
\hline \multirow{9}{*}{ Surgical } & Anesthesia & 9 & 77,8 & 44,4 & 88,9 & 88,9 & 22,2 & 88,9 & 77,8 & 66,7 & 77,8 & 88,9 & 77,7 & 55,6 \\
\hline & General Surgery & 12 & 0 & 83,3 & 100 & 91,7 & 25 & 100 & 83,3 & 83,3 & 91,7 & 100 & 83,3 & 58,3 \\
\hline & Traumatology & 12 & 16,7 & 66,7 & 41,7 & 100 & 58,3 & 66,7 & 83,3 & 91,7 & 91,7 & 91,7 & 75 & 50 \\
\hline & Otorhinolaryngology & 3 & 0 & 66,7 & 100 & 100 & 0 & 100 & 100 & 100 & 100 & 100 & 100 & 66,7 \\
\hline & Urology & 2 & 0 & 100 & 100 & 100 & 0 & 100 & 100 & 100 & 100 & 100 & 100 & 50 \\
\hline & Gynecology & 8 & 62,5 & 75 & 87,5 & 87,5 & 37,5 & 87,5 & 87,5 & 100 & 100 & 100 & 87,5 & 100 \\
\hline & Gynecology Midwives & 6 & 0 & 83,3 & 50 & 83,3 & 50 & 100 & 83,3 & 100 & 100 & 100 & 100 & 50 \\
\hline & Ophtalmology & 9 & 22,2 & 33,3 & 88,9 & 100 & 44,4 & 66,7 & 44,4 & 100 & 55,6 & 100 & 77,8 & 22,2 \\
\hline & Dermatology & 3 & 0 & 33,3 & 100 & 33,3 & 0 & 66,7 & 100 & 100 & 100 & 100 & 66,7 & 100 \\
\hline \multirow{5}{*}{$\begin{array}{l}\text { Central } \\
\text { Services }\end{array}$} & Quality of Care & 4 & 50 & 50 & 50 & 50 & 50 & 50 & 50 & 50 & 50 & 50 & 50 & 25 \\
\hline & Radiology & 8 & 12,5 & 37,5 & 37,5 & 62,5 & 25 & 37,5 & 50 & 50 & 50 & 100 & 62,5 & 87,5 \\
\hline & Physiotherapy & 13 & 7,7 & 61,5 & 30,8 & 23,1 & 30,8 & 46,2 & 100 & 100 & 92,3 & 76,9 & 69,2 & 30,8 \\
\hline & Rehabilitation & 4 & 0 & 75 & 100 & 100 & 0 & 100 & 100 & 100 & 100 & 100 & 75 & 50 \\
\hline & $\begin{array}{l}\text { Pathological Anat- } \\
\text { omy }\end{array}$ & 4 & 0 & 0 & 0 & 50 & 50 & 25 & 50 & 0 & 25 & 25 & 25 & 25 \\
\hline \multirow{5}{*}{$\begin{array}{l}\text { Primary } \\
\text { Care }\end{array}$} & $\begin{array}{l}\text { Family and Commu- } \\
\text { nity Medicine }\end{array}$ & 75 & 21,3 & 65,3 & 86,7 & 66,7 & 24 & 70,7 & 68 & 76 & 60 & 82,7 & 81,3 & 57,3 \\
\hline & Primary Care Nursing & 61 & 31.1 & 45,9 & 78,7 & 59 & 19,7 & 86,9 & 80,3 & 73,8 & 55,7 & 88,5 & 80,3 & 45,9 \\
\hline & $\begin{array}{c}\text { Primary Care Pedi- } \\
\text { atrics }\end{array}$ & 16 & 50 & 62,5 & 81,3 & 68,8 & 37,5 & 75 & 81,3 & 56,3 & 81,3 & 81,3 & 77,8 & 56,3 \\
\hline & $\begin{array}{l}\text { Primary Care Mid- } \\
\text { wives }\end{array}$ & 18 & 33,3 & 55,6 & 77,8 & 44,4 & 61,1 & 66,7 & 66,7 & 76,2 & 61,1 & 72,2 & 66,7 & 66,7 \\
\hline & Global & $\begin{array}{c}356 \\
(369)\end{array}$ & 23 & 62,1 & 77 & 69,7 & 27,5 & 80,3 & 77,5 & 77,8 & 69,1 & 88,2 & 82 & 59,8 \\
\hline
\end{tabular}




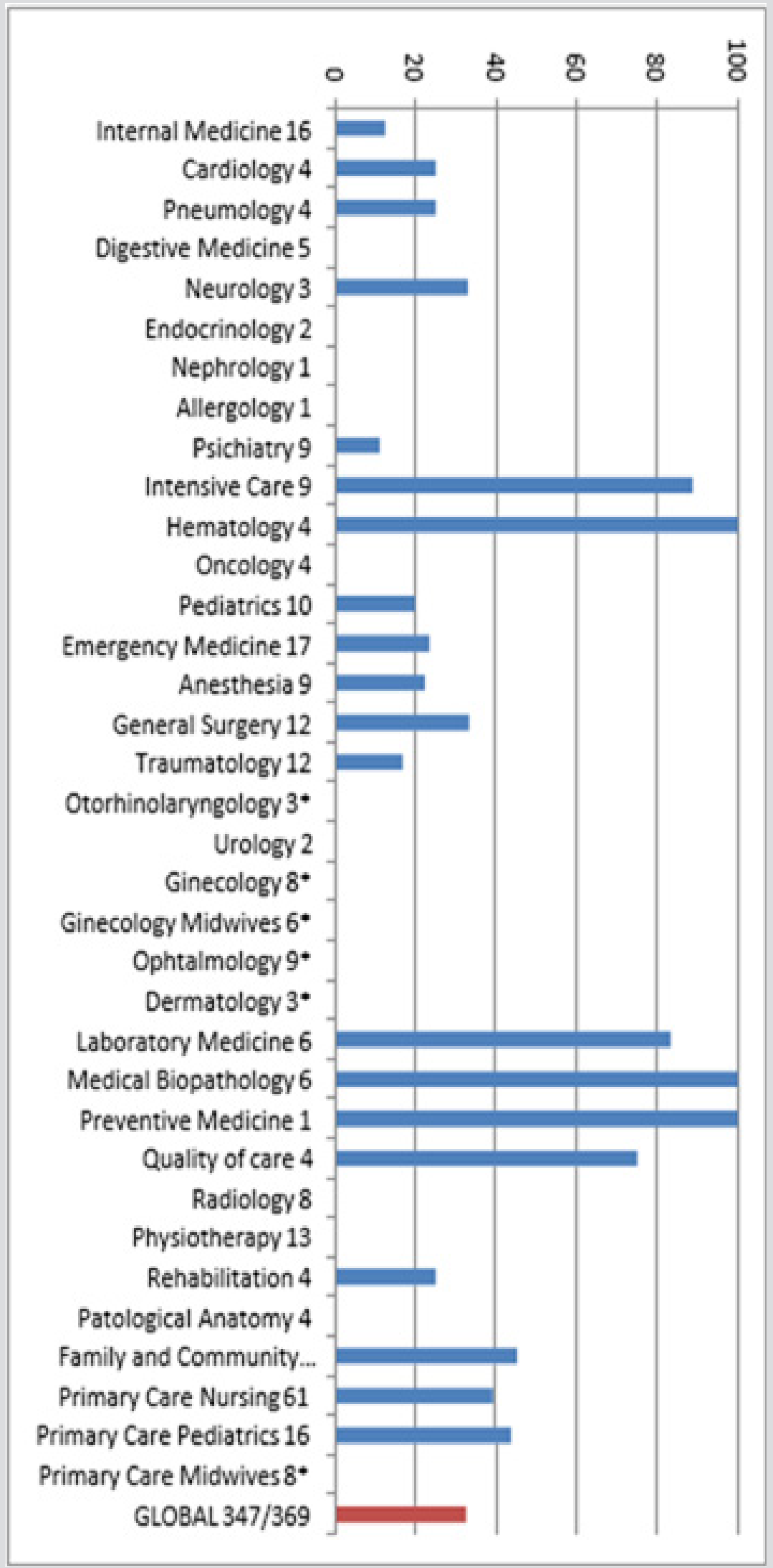

Figure 3: Knowledge of the Not - To - Do Recommendations (NTDR) in the different specialties. The shown number is the number of surveys received. Specialties marked with an asterisk $\left(^{*}\right)$ don't have DTDR. The final column in red shows the overall percentage of knowledge of the NTDR among the 347 health professionals who have recommendations. 


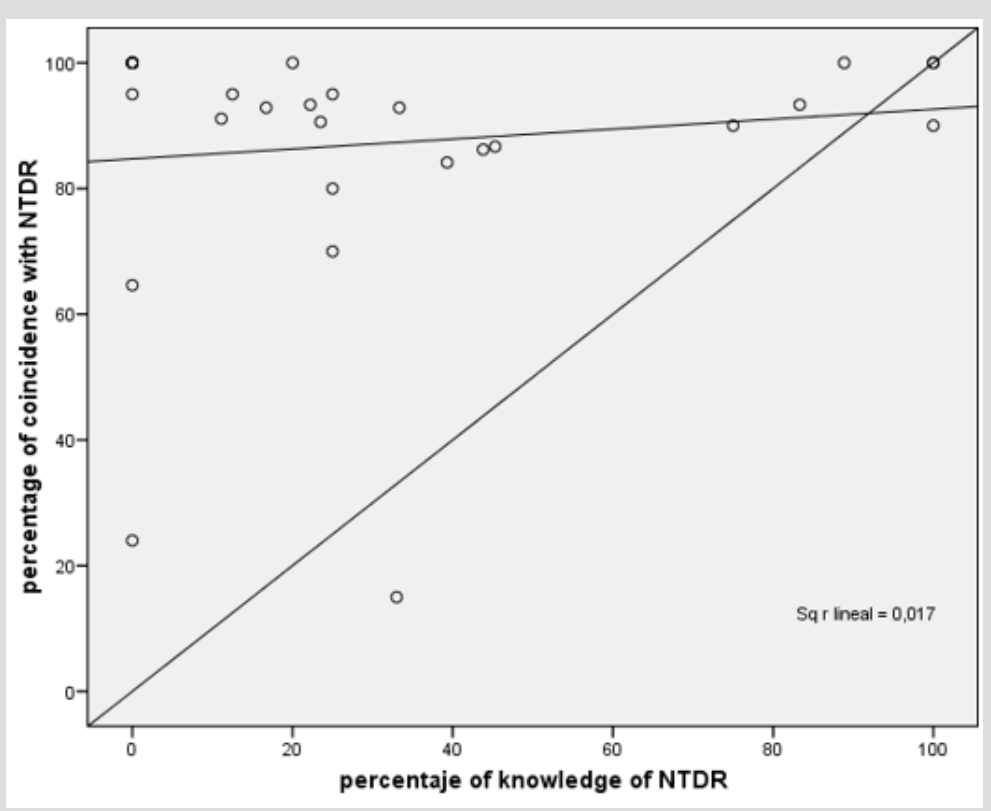

Figure 4: Scatter plot that shows relationship between the knowledge of NTDR and the coincidence in the daily performance with those Recommendations.

\section{Discussion}

The results of our work show an image of lights and shadows. There is much to improve in the field of use of NTDR. There is a deficit of the diffusion of recommendations of many scientific societies among its members; and even some scientific societies have not yet elaborated their NTDR, despite the impulse given by the Ministry of Health for its preparation. The change of work philosophy has arrived. Finally working in quality is the motor of the acts in the sanitary field at least theoretically. The FUPPS will promote the inclusion of these simple recommendations within the guidelines for welcoming new professionals to the hospital. It's very surprising the fact that although the knowledge of the NTDR is low, our usual practice is generally good and is not far from what is promoted by these recommendations. Although the IC is increasingly integrated into our daily practice, formation gaps about understanding the meaning and legal scope of the completion of this document are still detected. The knowledge of the NTDR in the different specialties is low. We discovered some exceptions. The high knowledge of these recommendations in the Anesthesia service may be due to the recent preparation of an IC document in this service. The dedication to Assisted Reproduction by the Gynecology service can also justify the adequacy of the responses of this service in the questions related to CI. The presence of specialties with a low number of members can distort the map of the percentages of answers. Also, the perception of tacit consent may also be different in different specialties. The global perspective is acceptable, but there are aspects to improve in all the questions raised and in all specialties.

The authors have found few published works similar to ours. Mira et al carried out an observational study with the distribution of a survey similar to ours among family doctors, nurses and paediatricians, all of them in several primary care centers in Spain [8]. Several questions are asked: knowledge about the existence of the campaign "Commitment for the Quality of Scientific Societies", and other dichotomous questions based on the NTDR to assess the level of knowledge. They have answers from 1904 professionals. The percentage of professionals with all the correct answers, an element that we have not valued in our work, is high $169.7 \%$ of family doctors, $92.5 \%$ of pediatricians and $40.6 \%$ of nurses). As in our work, despite not knowing this initiative, a high percentage of professionals responded appropriately to questions about NTDR ( $60 \%$ of Primary Care doctors and $90 \%$ of pediatricians). Similar works $[9,10]$ have a variable percentage of knowledge of these initiatives, with a tendency to be higher in the more recent work, which would have allowed a greater dissemination of these quality ideas among health professionals [8].

The study of Martín et al. [11] was carried out in highly complex hospitals. Up to $90 \%$ of the directors of the Clinical Unit of a hospital expressed their agreement with the diffusion of NTDR of the NICE; but these same answerers assessed these NTDR as useful, applicable and highly effective and efficient in minor percentages. $20 \%$ of the NTDR that were considered useful were not applied. There is not much more information about IC issue. Rodríguez Piñero et al. [12] carry out an observational work to know the opinion and general knowledge of patients about IC and their participation in Decision Making. A descriptive study was conducted with 120 patients randomly selected that made the survey in university hospitals in Galicia, Spain. Up to $84.21 \%$ of ICs were provided by non-medical personnel. Only half of the health professionals tried to involve the patient in the decision-making process. 
López Camps et al. [13] send a survey referring to bioethical indicators and the IQ of certain techniques to the heads of the Intensive Care Units (ICUs). Among the surveyed units, the information to relatives is daily (97\%); there is an information room prepared for this purpose (82\%); there are end-of-life care protocols (44\%), containment protocols (40\%), and a document of limitation of life support therapy (48.4\%). The performance of IC for several usual techniques in ICU is variable: tracheostomy (92\%), vascular intervention (76\%), extrarenal clearance $(25 \%)$. It is clear from this work that NTDR and IC are aspects whose implementation in ICUs must improve. The positive aspects of our study are important: the effort made to take a real-time photograph of the degree of knowledge of the NTDR and IC is enormous. The completeness of the sample of health professionals is over $50 \%$, so the data collected is a true reflection of the current situation.

Our work also has limitations. Although it was insisted to reflect in the answers the daily practice and not "what we would like to be done every day", it is probable that in many cases they answered more about intentions than about facts. Subjectivity bias is inevitable for this type of surveys. And the objective is purely descriptive. In a short period of time we will carry out the pertinent improvement actions: improve the learning and formation on IC in the health workers through a tutorial available in a lint of the intranet of the hospital; to include the NTDR within the well coming material that is delivered to the new workers (residents) in our hospital; etc. As a summary of our work, the Importance of IC [14] and NTDR is undeniable within the conceptual framework of what quality of care supposes at the present time.

\section{Acknowledgement}

The authors of this work would like to thank the members of the Functional Unit of Quality and Safety of the Patient of the hospital de Sagunt, and to Victoria Simón, its president for their help and the impulse given to the tasks of quality improvement in our health department; and to the health professionals of our health area, for complete this survey, without them this work could not have been carried out.

\section{Conflict of Interest}

This work has been carried out without any financial support. The authors declare that they have no conflicts of interest.

\section{References}

1. Reglamento Interno de la Unidad Funcional de Calidad y Seguridad del Paciente (UFCASP). Generalitat Valenciana. Link: www.san.gva.es/ documents/151744/6828879/Instrucción+3_2017castellano.pdf
2. Ley $10 / 2014$ de 29 de diciembre, de Salud la Generalitat valenciana. Link: www.san.gva.es/documents/156344/1654585/ley+10-2014+29+dic. pdf

3. Ley 8/2018 de 20 de Abril, de la Generalitat Valenciana de modificación de la Ley 10/2014, de 29 de diciembre, de la Generalitat, de Salud de la Comunitat Valenciana. Link: http://www.dogv.gva. es/portal/ficha_disposicion.jsp?L=1\&sig=003941\%2F2018\&url_ lis ta $=\% 26$ a m p \% 3 B a m p \% 3 B a m p \% 3 B C H K_ TEX T O_LI BRE\%3D1\%26amp\%3Bamp\%3Bamp\%3Btipo_search\%3Dlegislacion\%26amp\%3Bamp\%3Bamp\%3Bnum_tipo\%3D9\%26amp\%3Bamp\%3Bamp\%3Bsignatura\%3D004656\%2F2015

4. Ley $41 / 2002$, de 14 de noviembre, básica reguladora de la autonomía del paciente y de derechos y obligaciones en materia de información y documentación clínica. Link: https://www.boe.es/buscar/doc. php?id=BOE-A-2002-22188

5. Recomendaciones de no hacer. Compromiso por la calidad de las Sociedades Científicas en España. Link: http://www.mscbs.gob.es/ organizacion/sns/planCalidadSNS/cal_sscc.htm

6. Quecedo Gutiérrez (2016) Recomendaciones de "no hacer" de la Sociedad Española de Anestesiología, Reanimación y Terapéutica del Dolor. Proyecto "Compromiso por la calidad de las sociedades científicas”. Rev Esp Anestesiol Reani 63(9): 519-527.

7. Consentimiento informado. Link: http://www.san.gva.es/web/dgcal/ consentimiento-informado;jsessionid=D18C8B890AA110AFE8DF0614 FA6E1F12.appli7_node2

8. Mira JJ, Carrillo I, Pérez-Pérez P, Olivera G, Silvestre c (2018) Grado de conocimiento de la campaña Compromiso por la Calidad y de las recomendaciones de no hacer entre médicos de familia, pediatras y enfermería de Atención Primaria. An Sist Sanit Navar 41(1): 47-55.

9. Zambrana-García JL, Lozano Rodríguez-Mancheno A (2016) Actitudes de los médicos hacia el problema de las pruebas y procedimientos innecesarios. Gac Sanit 30(6): 485-486.

10. Colla CH, Kinsella EA, Morden NE, Meyers DJ, Rosenthal MB (2016) Physician perceptions of choosing wisely and drivers of overuse. Am J Manag Care 22(5): 337-343.

11. Martín S, Miñarro R, Cano P, Aranda JM Resultados (2015) de la aplicabilidad de las "do not do recommendations" del National Institute for Health and Care Excellence en un hospital de alta complejidad. J Healthc Qual Res 30(3): 117-128.

12. Rodríguez Piñero JE, Tabernero Duque MJ, Rodríguez Calvo MS (2018). Estudio descriptivo sobre la aplicación del consentimiento informado en centros sanitarios de Galicia (España). Cuadernos de Bioética 29 (95): 69-79.

13. López Camps V, MA García García, MC Martín Delgado, JM Anon Elizalde, N Masnou Burrallo (2017) Encuesta Nacional sobre los indicadores de calidad en Bioética de la SEMICYUC, en los servicios de Medicina Intensiva en España. Med Intensive 41(9): 523-531.

14. Sánchez López JD, Rodríguez I, Carriel Araya V, Moreno Martín ML (2018) Calidad asistencial. Importancia del consentimiento informado. J Healthc Qual Res 33(3): 179-180. 
ISSN: 2574-1241

DOI: $10.26717 /$ BJSTR.2019.20.003416

Miguel Angel García García. Biomed J Sci \& Tech Res

(C) (P) This work is licensed under Creative

Submission Link: https://biomedres.us/submit-manuscript.php

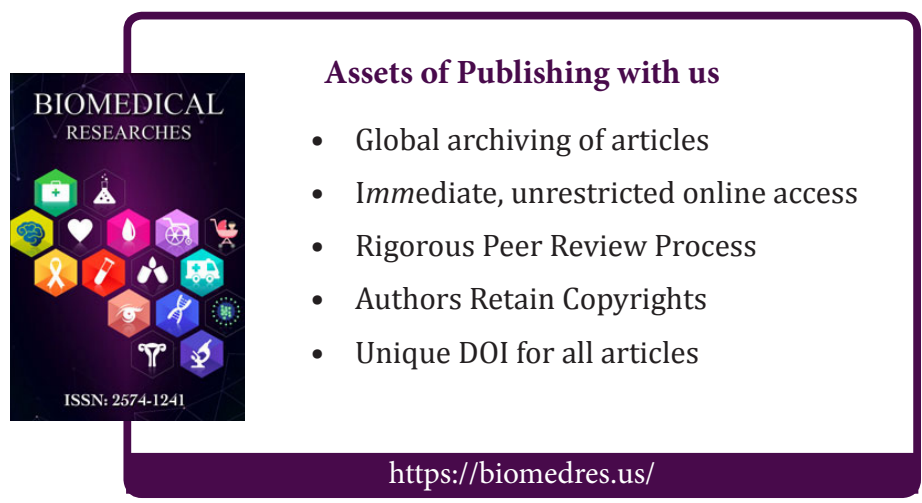

